
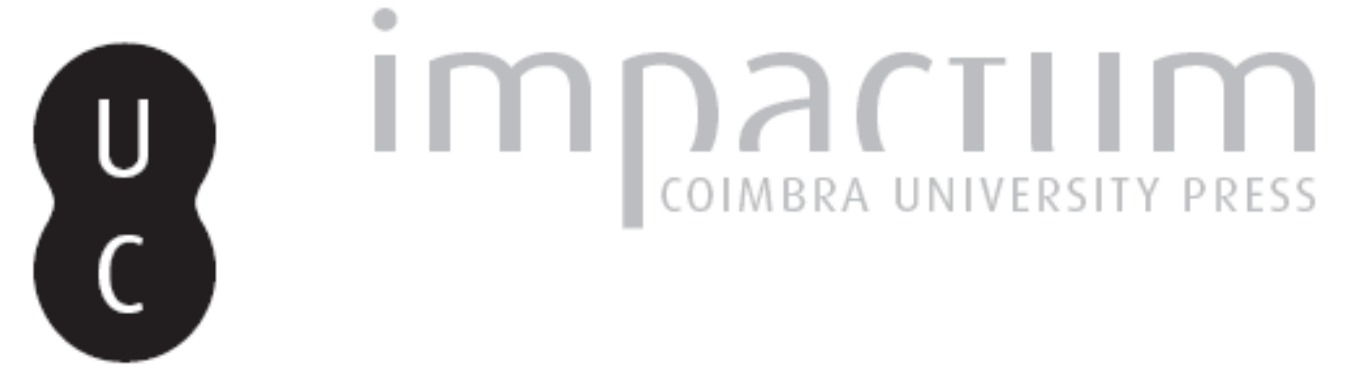

\title{
Potencialidades del microrrelato en Internet
}

Autor(es): $\quad$ Ferreira, Ana Sofia Marques Viana

Publicado por: Centro de Literatura Portuguesa; Imprensa da Universidade de Coimbra

URL persistente:

URI:http://hdl.handle.net/10316.2/39104

DOI:

DOI:http://dx.doi.org/10.14195/2182-8830_4-2_10

Accessed : $\quad$ 26-Apr-2023 12:29:05

A navegação consulta e descarregamento dos títulos inseridos nas Bibliotecas Digitais UC Digitalis, UC Pombalina e UC Impactum, pressupõem a aceitação plena e sem reservas dos Termos e Condições de Uso destas Bibliotecas Digitais, disponíveis em https://digitalis.uc.pt/pt-pt/termos.

Conforme exposto nos referidos Termos e Condições de Uso, o descarregamento de títulos de acesso restrito requer uma licença válida de autorização devendo o utilizador aceder ao(s) documento(s) a partir de um endereço de IP da instituição detentora da supramencionada licença.

Ao utilizador é apenas permitido o descarregamento para uso pessoal, pelo que o emprego do(s) título(s) descarregado(s) para outro fim, designadamente comercial, carece de autorização do respetivo autor ou editor da obra.

Na medida em que todas as obras da UC Digitalis se encontram protegidas pelo Código do Direito de Autor e Direitos Conexos e demais legislação aplicável, toda a cópia, parcial ou total, deste documento, nos casos em que é legalmente admitida, deverá conter ou fazer-se acompanhar por este aviso.

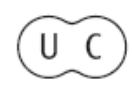



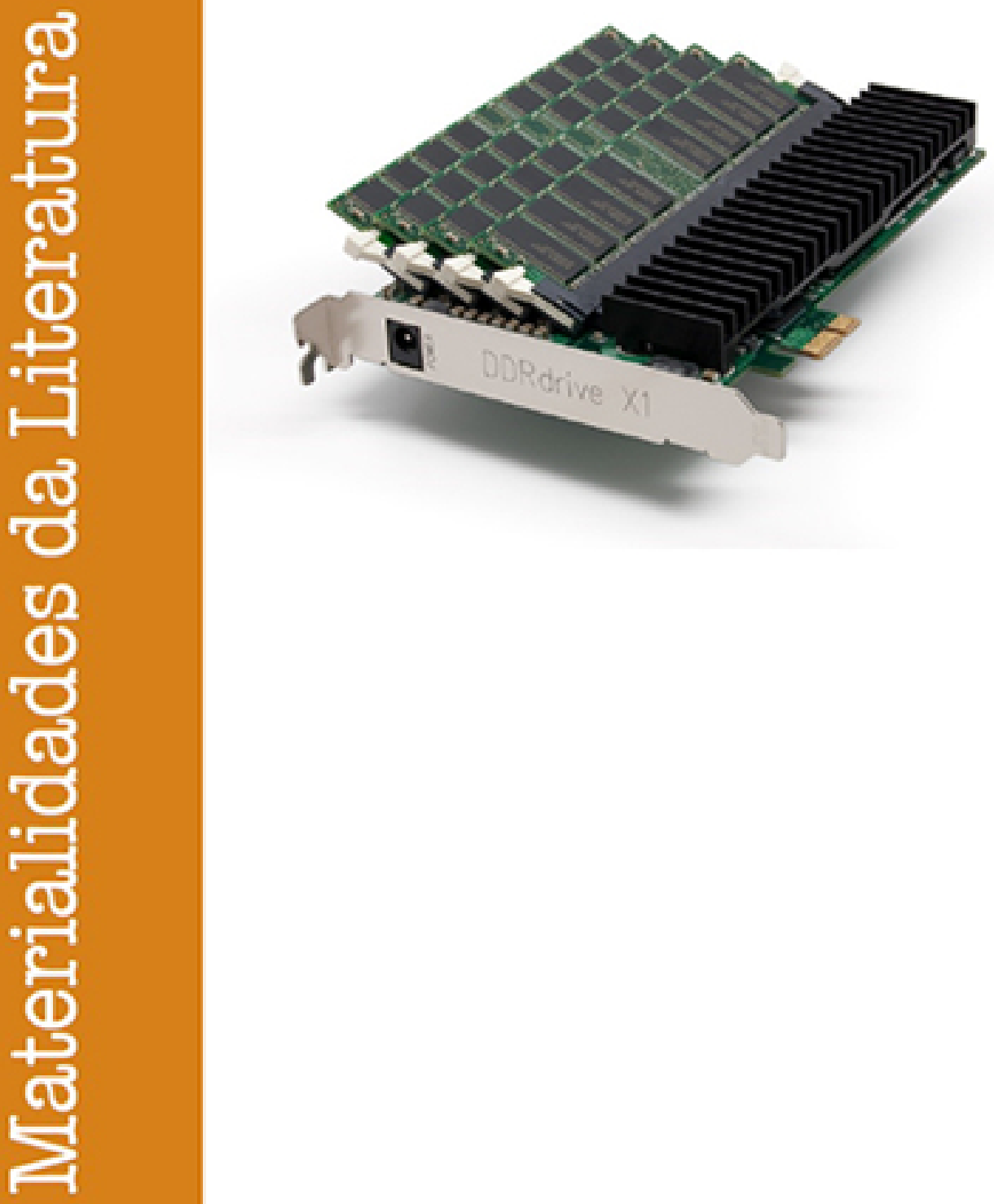

Vol. 4.2 (2016) ISSN 2182-8830

'Estudos Literários Digitais 2'

Manuel Portela e António Rito Silva (orgs.) 


\title{
Potencialidades del Microrrelato en Internet ANA SOFIA MARQUES VIANA FERREIRA

\author{
Universidad de Salamanca
}

\begin{abstract}
Resumen
La crítica generada en torno al microrrelato viene demostrando que esta categoría textual literaria se ha revelado paradigmática del modo de estar y pensar del ser humano de hoy. Su naturaleza escueta, sugerente e híbrida le permite entrar fácilmente en diálogo con discursos de otros ámbitos. En concomitancia, su difusión por Internet en los últimos años y desde distintos circuitos comprueba que es en Internet donde halla el hábitat ideal para desarrollar sus potencialidades y que en larga medida es la responsable por su actual éxito. Por ello, será de vital importancia acercarnos a este discurso partiendo de la premisa de que, sin que haya nacido en el mundo tecnológico tal y como hoy lo concebimos, el microrrelato se ha servido de las características de la esfera virtual para propagarse y volverse un fenómeno altamente democratizado, sobre todo desde la creación. Palabras-clave: microrrelato; Internet; hibridación genérica; intertextualidad; meme.
\end{abstract}

\section{Abstract}

The criticism generated around the short short story has shown that this literary text category is paradigmatic of contemporary human being's way of being and thinking. Its brief, quick, suggestive and hybrid nature allows it to absorb other speeches from other areas, as well as to enter into dialogue with them. Concurrently, its dissemination through the Internet in recent years and through different circuits proves that it is on the Internet that this kind of fiction finds the ideal habitat to develop its potential. Internet publication also contributes to its current popularity. From this approach, it is very important to address this discourse on the premise that without being born in the technological world as we conceive it today, the short short story has taken advantage of the features of the virtual sphere to spread and become a highly democratized phenomenon, especially from the perspective of their creators. Keywords: short short story; Internet; generic hybridization; intertextuality; meme.

\section{Introducción}

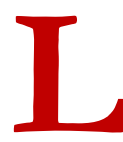

a inmersión de la Literatura en el espacio virtual vino a fomentar, recuperar y a desafiar contenidos y formas desde el territorio de la creación poética. De entre las varias que podríamos enumerar, el microrrelato, el aforismo, el haikú son apenas algunos ejemplos de formas textuales literarias hiperbreves que han ganado actualmente un importante acervo en territorios ficcionales como el hispánico y que prometen seguir consolidándose en el actual panorama, conquistando a una porción importante de lectores y erigiendo una notable atención de la crítica literaria. Si bien es 
cierto que no todas las literaturas se rigen por las mismas fuerzas motrices y según los mismos denominadores comunes, hay muestras de que territorios literarios como el inglés, el español, el argentino o el mexicano, por solo citar algunos, han manifestado de un modo o de otro cierta visibilidad a esta cuestión.

Para corroborarlo, nos bastaría con centrar nuestra mirada en el caso de la literatura de ámbito hispánico, desde seis vectores: 1) el surgimiento de casas editoriales y colecciones especializadas en el género microficcional Menoscuarto, Páginas de Espuma, Thule; 2) la explosión del número de autores que en la última década se ha aficionado a la hiperbrevedad literaria, derivada, entre otras causas, de la conformación teórica del microrrelato, su reconocimiento como nuevo discurso y consecuente visibilidad de sus cultivadores; 3) la multiplicación de antologías que se han editado y cuyos criterios de selección son muy vastos y heterogéneos: desde antologías de microrrelatos de origen clásica (Después de Troya. Microrrelatos hispánicos de tradición clásica, Palencia: Menoscuarto, 2015), obras que recorren la presencia de este discurso literario en bitácoras y blogs personales (Deantología, la logía del microrrelato, Madrid: Talentura, 2013), antologías que se ciñen a motivos muy concretos (MicroQuijotes, Barcelona: Thule, 2005; ¡Nocauts! Microrrelato internacional de boxeo. Puebla: BUAP, 2015), a obras que recogen las tendencias más actuales del microrrelato español contemporáneo (Mar de Pirañas. Nuevas voces del microrrelato español, Palencia: Menoscuarto, 2012), o que se ciñen al caso argentino o mexicano (El límite de la palabra. Antología del microrrelato argentino contemporáneo. Palencia: Menoscuarto, 2007; Alebrije de palabras: Escritores mexicanos en breve. Puebla: BUAP, 2013) y a otras de carácter más vasto y generalista, como La otra mirada. Antología del microrrelato hispánico, (Palencia: Menoscuarto, 2005); 4) los concursos literarios que se convocan sobre todo por las redes sociales y que rebasan con creces la centena de convocatorias; 5) las secciones de publicaciones periódicas dedicadas al microrrelato y otras formas breves y 6) la explosión de la actividad crítica y la labor investigadora alrededor del microrrelato en las últimas dos décadas, acomodada en sus diversas formas: artículos, libros de naturaleza teórica y crítica, tesis doctorales y congresos dedicados exclusivamente a la microficción.

Las razones que están por detrás de este suceso - que cada vez se acerca más bien al éxito - no se pueden atisbar, solamente desde sus mismas características intrínsecas - que se materializan en una extraordinaria capacidad sugerente, el golpe de ingenio y la seducción en impactar con lo mínimo de palabras, confluyendo en el less is more propugnado por la Escuela de la Bauhaus - sino que se puede perseguir algunas razones histórico-literarias, contextuales y luego una serie de compatibilidades con Internet que conceden al lector y/o usuario una destacada familiaridad con estos discursos.

Empecemos por las razones que se formulan desde el campo de la Historia de la Literatura y que tienen que ver con la gestación y apogeo de los movimientos de vanguardia, de experimentación y de rechazo a las fórmulas 
provenientes del realismo decimonónico y que lo formulamos sosteniéndonos en las palabras de Lagmanovich, una referencia primordial en los estudios críticos y teóricos del microrrelato:

En el caso de las letras, en diversas literaturas resulta perceptible el acortamiento de las novelas, los cuentos y los ensayos. El proceso ya se había cumplido en la poesía: primero en casos tales como el simbolismo francés, el modernismo hispánico o la literatura inglesa de finales de siglo XIX; y luego en el período de nuestras vanguardias (que coincide temporalmente con el 'modernismo' anglosajón), período de acuciosa experimentación formal. El proceso continuará a todo lo largo del siglo pasado y parece definitivamente establecido en el que ahora transitamos. (Lagmanovich, 2005: 15)

Esta tendencia, que no es necesariamente la imperante en la Literatura Occidental del siglo XX y XXI - sino una tendencia más - no encuentra por lo tanto sus orígenes con Internet, sino que hay todo un desarrollo por detrás que viene, eso sí, a ser impulsado, a manifestarse con mucho más vigor y a generar todo un aparato crítico que lo respalda, a partir del progreso tecnológico y de la impactante involucración del sujeto común en la Red. Si nos adentramos en el caso portugués, vamos a encontrar a escritores como Almada Negreiros, Mário Henrique-Leiria, y, décadas más tarde, Adília Lopes, Paulo Kellerman, Rui Manuel Amaral, Gonçalo M. Tavares, Afonso Cruz, José Mário Silva, Pedro Paixão, Henrique Manuel Bento Fialho y Joana Bértholo, creadores que han publicado sus obras sin el respaldo de los medios tecnológicos virtuales.

Nos ceñiremos en el presente trabajo a una de las ramificaciones actuales de la hiperbrevedad literaria, el microrrelato -microconto en portugués, flash fiction o short short story en inglés- considerado por algunos investigadores como el cuarto género narrativo. ${ }^{1}$ Trataremos a continuación de delimitar las fronteras del concepto, recurriendo para tal, en dos definiciones de microrrelato propuestas, en el primer caso, por Neus Rotger y Fernando Valls y luego por Marcelo Spalding:

El microrrelato, como su propio nombre indica, podría decirse que es un texto narrativo breve en el que se cuenta una historia de la manera más concisa e intensa posibles, y en el que la narratividad se impone incluso a la brevedad. (Neus Rotger y Fernando Valls, 2005: 10)

Miniconto é um tipo de conto muito pequeno, digamos que com no máximo uma página, ou um parágrafo. Alguns dizem que ele é o primo mais

${ }^{1}$ Vid Andres-Suárez, Irene (ed.) (2012), Antología del microrrelato español (1906-2011). El cuarto género narrativo. Madrid: Cátedra. Letras Hispánicas. 
novo do poema em prosa, outros apontam as fábulas chinesas como origem, de certo é que desde meados do século XX o conto tem experimentado - com sucesso - formas extremamente breves a partir de textos de gente como Cortázar, Borges, Kafka, Arreola, Monterroso e Trevisan. (Spalding, 2007: 1)

Como podemos observar, la confluencia de rasgos como la narratividad, la brevedad, la concisión e intensidad parecen conformar la identidad del microrrelato, cualidades estas que lo hacen enmarcarse de otros subgéneros literarios muy próximos, como es el poema en prosa, el epigrama o la anécdota, basándose sobre todo en una condición ficcional narrativa, marcada por la parquedad del cuerpo textual.

Es precisamente a partir de estas características, que podemos enunciar la existencia de una serie de compatibilidades entre el microrrelato y la propia World Wide Web, y que, tal como trataremos de desarrollar a continuación, se manifiestan en la extrema brevedad, la concisión y la tensión narrativas, el carácter sugerente, tridimensionalidad y elipsis, el proceso de co-autoría y el carácter paródico y propensión replicante del mensaje y la comodidad hacia lo transdiscursivo y transmedial.

\section{Extrema brevedad, concisión y tensión narrativas}

Aparte de la seducción connatural que la narrativa produce - pensemos desde luego que el ser humano se construye a partir de narraciones que le facultan construir una identidad singular -, el carácter efímero de los discursos mínimos, aliado a estrategias discursivas como la concisión, ${ }^{2}$ coopera en la obtención de un aura de trascendencia e inconmensurabilidad muy particular, por la simple regla de proporcionalidad inversa: a la menor expresión verbal, mayor la potencialidad de sugerencia e impacto. Por otras palabras, la culminación de la decantación lingüística se logra con una alta proclividad a la conmoción y expansión de significados en el proceso de lectura. Lo que hay en común en estos tres recursos (la brevedad, la concisión y la tensión) asienta en el requisito de quitar los ángulos muertos de la escritura ficcional y despojarla de elementos accesorios que ralenticen o anestesien la narrativa,

\footnotetext{
${ }^{2}$ Pese a que los estudios actuales abogan por delegar mucho más importancia, a la hora de definir los rasgos del microrrelato, a la concisión frente a la brevedad recordemos que su distinción se ubica, respectivamente, en una cualidad estructural de un texto frente a un mecanismo interno de constricción de contenido que afecta la estructura formal. En nuestra opinión la brevedad juega un papel también importante para despertar nuestra curiosidad y atención y que nos lleva visualmente a acercarnos a estos textos. Pensemos desde luego que esto se refleja muy bien en la Red Virtual, en donde un texto largo, por su gran propensión a la monotonía, no es visualmente atractivo y, desde el punto de vista de las expectativas, quiebra con más facilidad el interés del lector.
} 
como son las descripciones y las corrientes de conciencia. A veces esa regla alcanza magnitudes que desafían los límites de la sobriedad, como en:

Queria ser escritor.

Começou mentindo para os pais.

(Samir Mesquita, 2007)

\section{Principios}

Mujer de un solo hombre, nunca mantenía relaciones largas.

(Belén Lorenzo, 2011)

\section{Serial Killer}

Solícito, deu-lhe uma mãozinha. Só que não era a dele.

(Tristinho, 2010)

Esta característica, la extrema brevedad, que es apuntada como una de las insignias del plano de apariencia inmediata del microrrelato, permite que estos textos circulen y penetren con mucha facilidad en un territorio tan vorágine y competitivo como es el ciberespacio, que da muestras de galardonar la brevedad y la disolución - en tiempo, espacio y materia - de fronteras interdiscursivas. Desde este planteamiento, si el hipertexto, mecanismo de estructura secuencial y de realización jerárquica de contenidos en la Red, produce efectos de fragmentación y de contaminación lingüística, creemos que el microrrelato instaura, en cierta medida, un modo de aprehensión cognitiva hacia esos efectos producidos por circulación en Internet, con claras implicaciones a nivel de la configuración discursiva (desde luego la precisión lingüística y dirección hacia una unidad de efecto serán destrezas que, desde la entidad autoral, deben ser constantes). Sostenemos, por lo tanto, la idea de que este discurso responde a las necesidades de simultaneidad, fragmentación y diálogo interdiscursivo, implicadas en el proceso de lectura en Internet. Tal y como lo expresa Laura Borràs Castanyer:

Imagino que la fragmentación, la multilinealidad y sus consecuencias, la más desconcertante de las cuales seguramente es la pérdida del control, son algunas de las principales causas de la incertidumbre que el hipertexto crea en nosotros. Estamos habituados a que los relatos, casi por definición, se inscriban en el tiempo, impliquen un orden, un desarrollo secuencial. (Castanyer, 2005: 51)

Como consecuencia del carácter reducido del código lingüístico y de la presencia de un pendón narrativo, la acción o acciones inscritas en estos textos tienden a coronarse de modo casi instantáneo, lo que nos permite hablar de una alta velocidad del mensaje narrativo. Por ello mismo, a los microrrelatos les han sido atribuidas muchas denominaciones que delatan su 
condición rauda, como "flash fiction", "blasters", "relatos vertiginosos", "cuento instantáneo", etc.

Es esta misma velocidad y lacónica extensión discursiva que, involuntariamente, nos hemos acostumbrado a hallar en Internet, y que nos ha hecho, por la estructura caótica, la continua estimulación y la dispersión de la información, acomodar nuestra visión $y$, en definitiva, nuestro cerebro, a una intolerancia a textos largos y monótonos y a la discontinuidad del proceso de lectura. Pensemos en nuestra experiencia como usuarios de la web, que, sin el uso de herramientas de bloqueo en los navegadores, nos habitúa a ventanas pop-ups que saltan sin aviso previo, a los hipervínculos, a avisos de mensajes que nos llegan a la bandeja de entrada, a conversaciones en chats que nos interrumpen alguna lectura u otra actividad en la Red, o la publicidad que se adjunta en rincones estratégicos.

Una de las consecuencias de esa acumulación de materia textual es la dispersión de la capacidad de concentración. En esa misma clave se expresa Nicholas Carr, en su obra fundamental Superficiales. ¿Qué está haciendo Internet con nuestras mentes?, cuando afirma:

cuando nos conectamos a la Red, entramos en un entorno que fomenta una lectura somera, un pensamiento apresurado y distraído, un pensamiento artificial. Es posible pensar profundamente mientras se navega por la Red, como es posible pensar someramente mientras se lee un libro, pero no es éste el tipo de pensamiento que la tecnología promueve y recompensa. (Carr, 2011: 143-144)

La Red es, por su mismo diseño, un sistema de interrupción, una máquina pensada para dividir la atención. Ello no resulta sólo de su capacidad para mostrar simultáneamente muchos medios diferentes. También es consecuencia de la facilidad con la que puede programarse para enviar y recibir mensajes. (Carr, 2011: 162)

\section{Carácter sugerente, tridimensionalidad y elipsis}

La máxima expresión con el máximo ahorro de palabras nos lleva a concebir el microrrelato como un organismo discursivo vertical, en la medida en que la concisión, aliada a la omisión de contenido latente (elipsis) y al recurso a estrategias discursivas como la ambigüedad semántica o la sugerencia, le concede profundidad.

En términos metafóricos y en cierta medida, esta cuestión de la profundidad - o lo que es lo mismo, la tridimensionalidad - se puede emparejar con la presentación de la información, teorizada por Espen Aarseth (1997), tanto en el ordenador como en la Red, bajo scriptons (es decir, la instancia textual que surge en la superficie) y textons (el código que le subyace y que no es 
inteligible al usuario común). El microrrelato, en su esencia, debe presentar una dimensión que se expande en su carga sugerente/inmanente, que no está procesada textualmente, pero que se encuentra de algún modo configurada, preparada y proyectada para expandirse Ahora bien, la elipsis narrativa ocurre, mediante elementos presentes, a través de la sugerencia de elementos ausentes, aspecto que contrasta con la explicitud y el carácter manifiesto de las reglas que componen un texton. Por ello mismo, la elipsis narrativa emana de un superávit de sentido creado por la indeterminación y la ambigüedad que no funciona por una codificación precisa, sino por hacer implícitos elementos que no se han materializado textualmente. He aquí la principal diferencia entre los dos tipos de virtualidad vigentes en el microrrelato y en Internet.

Algunas teorías literarias se basan en imágenes para aclarar precisamente el concepto de la tridimensionalidad del código lingüístico en la narrativa. La más conocida corresponde a la del iceberg, de Hemingway, que aboga por la presencia de un campo de significación oculto y desproporcionalmente mucho más vasto y hondo que el campo de visibilidad ofrecido por la materia visual que es la palabra escrita, pero otras han surgido más recientemente, como la Poética Cuántica, de Juan Pedro Aparicio, que prefiere decantarse por la referencia a las Ciencias Físicas, a una parte de la materia que prevalece en el Universo, la materia oscura que, no siendo detectable a la vista, se rige por la ley de la elipsis (Aparicio, 2008: 491-495).

Desde este planteamiento, podemos decir que ambas entidades, microrrelato e Internet, comparten un mismo principio: la apariencia simplificada y visualmente sencilla y sobria se sostiene en andamios más o menos complejos a los que idealmente solo determinados sujetos pueden acceder y manejar. El microrrelato se aproxima, de este modo, a la lógica de las formas de comunicación breves y modulares típicas de la comunicación de la Web 2.0 como son los blogs, Facebook, Twitter y otras plataformas sociales, conservando su unidad narrativa formal. En el microrrelato "Sem título 2", de Laís Chaffe se enuncia:

Sem titulo 2

- Irmã?

- Sim, padre?

— Não aconteceu nada aqui, está bem?

— Louvado seja Deus Nosso Senhor.

- Amém.

(Laís Chaffe, 2013)

Mediante el recurso único al estilo directo, el lector se enfrenta a un texto que necesariamente se radica en el silenciamiento: por una parte, la escena presentada carece de todo el contexto, como si recortada y aislada de un texto formalmente más dilatado. De los personajes, el lector, por las pistas 
dejadas en el tratamiento empleado entre los mismos, concluye con facilidad tratarse de un cura y de una monja, no existiendo para el caso presentaciones o descripciones que les otorguen una identidad singular. Por otra parte, la misma sustancia narrativa implícita en el diálogo entre los intervinientes se basa en una acción que, por motivos no explicitados, debe omitirse. He aquí donde se deben activar un conjunto de inferencias que den un sentido al requisito de enmascaramiento y sigilo presentes en el contenido de esa conversación. Las posibilidades que pueden completar ese vacío de información pueden ser varias; sin embargo, la hipótesis de interpretación que podría ganar más fuerza, por el estatuto clerical de los personajes, es la de una consumación de la relación amorosa entre ambos, situación que, como sabemos, dentro del seno eclesiástico está totalmente interdita.

Como vemos, en ningún momento se hace referencia en el texto a cuestiones como la castidad eclesiástica, pero su inclusión en el horizonte interpretativo del lector, debidamente justificada por el vacío textual dejado en el microrrelato, es clave para dar un sentido, motivo y pertinencia a un texto tan escueto como el de Chaffe.

Tratándose, por ende, de un proceso de lectura más o menos complejo, que incita menudas veces y casi siempre a una relectura o a la suspensión de la misma para interpretar esas señales, que el aspecto que más se premia y que más fruición produce en el microrrelato es la estimulación cognitiva que suscita en el lector, activando su imaginación en el descifre de las camadas implícitas en las palabras del texto. Este modo de participación - que origina una especie de complicidad con el universo sugerido por el texto, toma la forma de una implicación cognitiva en el proceso de inferencias que el texto desencadena. Al contrario de lo que se pueda deducir, no es fácil conseguirse un buen microrrelato, por la exigencia de lograr sugerir o querer decir mucho en su mínima expresión lingüística y por la adecuación de las palabras a las exigencias de contenido del propio texto. Como consecuencia, el lector debe percibir que la esencia del microrrelato se encuentra encapsulada y que hay que hacer un esfuerzo de detenimiento y asimilación de lo que está entrañado. Desde este planteamiento, el escritor de microrrelatos espera a que sea el lector quien tome una participación activa en el alcance del significado del texto y que rellene los huecos dejados adrede desde la instancia creadora. Ahora bien, si esta interactividad diferida suele ocurrir en el microrrelato, independientemente de su superficie de difusión, si estamos hablando de microrrelato en la Red, eso se plasma de modo mucho más directo y expuesto. Pensemos, tal como Carr lo hizo (2011: 245), que Internet responde a un sistema altamente bidireccional, es decir, asienta en una lógica de cooperación e interacción entre los distintos intervinientes. $\mathrm{Y}$ es que no solo nos deja enviar y recibir mensajes, sino que incita en larga escala a que ello se produzca: los marcos que siempre están presentes en Facebook que instigan a contestar al “¿qué estás pensando?” o a comentar alguna publicación ajena, así como en los blogs, en cuya gran parte se permite a los visitantes que comen- 
ten y hagan una apreciación de cada publicación allí inscrita. Y eso es lo que permite que la interacción autor-lector sea una de las estrategias de acercamiento recurrentes en la Red entre los distintos agentes implicados en el proceso de escritura y lectura, proporcionando incluso la democratización generalizada del mismo proceso. De todas las redes sociales virtuales existentes, es tal vez Facebook, por su interfaz y por el gran apelativo que produce en estar constantemente conectado, la red que mejor refleja ese carácter democrático, en donde ya se crean grupos con una dinámica organizada y persistente que permite a todos los participantes acceder a los textos de los demás, adjudicar su opinión y dar su propia contribución, muchas veces de forma competitiva, en la actividad. Hablamos de grupos como "Escrita de Microficção", "Microrrelatos" o "The Flash Fiction Challenge 2015”.

\section{Carácter paródico y propensión replicante del mensaje}

A continuación, nos detenemos en un rasgo que, pese a que constituya más bien una tendencia, no deja de ser una de las divisas más interesantes y enganchadoras del microrrelato y que tiene que ver con una postura paródica de imitación formal y de distanciación crítica, llegando a manifestarse en posturas más irreverentes y burlonas. Esta singularidad le confiere proactividad a este discurso literario en cuanto al diálogo y rescate de textos que en un principio son familiares o de fácil alcance para el lector, en la mira de que este pueda llegar a su entendimiento. Y de no ser así, el hecho de estar conectado a la web facilita la descodificación del mensaje a través del recurso a los motores de búsqueda. Esto implica decir que el uso de fórmulas intertextuales es un procedimiento muy recurrente en este discurso, hecho que proporciona una lectura vertical y no linear. En plan metafórico, podemos hablar de una hiperconectividad del mensaje:

Yo conocí al griego Ulises. De regreso a su hogar, una tormenta lo había sacado de curso y su barco había naufragado finalmente en las costas de La Habana. Sin documentos que avalaran su nacionalidad lo confundieron con un cubano más. Era ya un anciano, pobre y harapiento. Había perdido toda esperanza de volver a su hogar; sin embargo siempre estaba dispuesto a enseñar a los isleños el difícil arte de construir balsas. Si no fuera por él jamás habríamos escapado de la isla. (Centurión, 2009)

El texto que Sandro Centurión nos presenta tiene la pretensión de aportar, en un nivel paródico, una nueva versión, o actualización, de la Odisea. El desconocimiento de la trama homérica no impide la comprensión y legibilidad del texto de Centurión, pero le quita eficacia y fuerza narrativa, ya que se pierde el valor y gesto reescritural, que aquí son la base para entender la intención del autor. Como se puede apreciar en este texto, dos realidades to- 
talmente anacrónicas y distintas (una ficcional y otra histórica) se fusionan para explicar, irónicamente, un suceso real: la capacidad de salida de Cuba por vía marítima por parte de sus propios habitantes. Según el texto de Sandro, Ulises no había naufragado en la isla de Calipso, sino en La Habana en un momento mucho más reciente que el período en el que se ancla el texto homérico y es gracias a este hecho que los cubanos lograron aprender el arte de construir balsas. Esta postura de contradecir y rectificar críticamente los textos canónicos, tan frecuentemente explorado en la literatura contemporánea, sirve también al microrrelato para desplegar sus posibilidades de actuación, en un ejercicio que, tal como mencionamos anteriormente, desafía al lector y al conocimiento cultural y del mundo que posee.

Partiendo de los razonamientos defendidos en la obra The selfish gene ("El gen egoísta”), de Richard Dawkins, y de su aplicación al ámbito literario empleada por el autor mexicano Jorge Volpi, del mismo modo que, y citamos, "los rasgos genéticos se transmiten por replicación de los genes, [también] los rasgos culturales se transmiten por replicación de los memes o unidades de información cultural". Lo que con esto se defiere es que también en la cultura existe transmisión y autorreplicación de sus unidades mínimas - los denominados memes - que se generan a partir de un proceso construido y artificial como es el propio lenguaje. Lo que implica decir que, perteneciendo cualquier texto literario a la rama del Arte, Cultura y Saber, también él, si reúne cualidades buenas, es susceptible de replicación. Y cuanto mejores sean las ideas que subyacen a un texto, mayor la probabilidad de constancia del proceso de reproducción de las mismas. Si trasladamos esta concepción al hecho de que el microrrelato, actualmente, constituye la subcategoría literaria que con más entusiasmo y afán genera procesos de reescritura, intertextualidad, parodia y tributo a objetos y materias extra e intraliterarios, podemos comprobar que el microrrelato no solamente se distribuye con facilidad en la Red por sus características formales, sino que las conexiones que a menudo establece entre otros textos producen un efecto de propagación mucho más estimulante y contagioso. Es como si habláramos, en términos de programación informática, de esos pequeños fragmentos de código que son los snippets que son o pueden ser reusables.

Con respecto a aquel que es el más conocido microrrelato de tradición hispánica, "El dinosaurio" de Augusto Monterroso, el propio motor de búsqueda de Google refleja esa que es la postura subversiva de los tiempos contemporáneos, a través de la inserción de sugerencias de búsqueda totalmente irónicas y burlonas: 
C Q augusto monterroso el dinosa

$Q$ augusto monterroso el dinosa - Búsqueda de Google
$Q$ augusto monterroso el dinosaurio
$Q$ augusto monterroso el dinosaurio pdf
$Q$ augusto monterroso el dinosaurio resumen
Q augusto monterroso el dinosaurio completo
Q augusto monterroso el dinosaurio libro

Figura 1. Captura de pantalla de una pesquisa en el motor de búsqueda de Google.

También en perfiles de Twitter se recrean réplicas y se procede con mucha frecuencia al efecto remix, como lo define Cassany (2012: 34), producidas por cualquier usuario sobre el microrrelato consagrado. De este modo, vamos a encontrar tweets como:

gerardo tecé @gerardotc· 6 de jan de 2014

Cuando despertó el dinosaurio todavía estaba allí. Y le dijo lo típico: Mira, Diplodocus, me lo he pasado bien, pero no quiero nada serio.

Gòmez de la Sorna@odradek1·6 de ago de 2013

Cuando despertó sepultado hasta la pituitaria por un colosal alud de excremento, el dinosaurio todavía estaba justo encima. \#Microcuento

Max Van Der Chasquen@MaxvanderChasqu ·25 de jun de 2013

Cuando despertó, el dinosaurio todavía estorbaba allí.

Augusto Monterroso@GustoMonterroso·25 de jun de 2013

Cuando despertó, después de *100 versiones* de El Dinosaurio, el maestro Monterroso todavía estaba allí. \#microliteratura

Gòmez de la Sorna@odradek1·27 de fev de 2013

Hoy me siento bien, un Balzac: estoy terminando de escribir El Dinosaurio. \#MiFiTi

\section{Más allá del canal de difusión}

Hasta el momento, hemos estado viendo las particularidades del microrrelato y su compatibilidad en las múltiples plataformas de interacción social disponibles en Internet. Dadas estas mismas características, hemos querido reflejar la favorable adecuación formal e interna del microrrelato a estas mismas plataformas en lo que de difusión concierne. Muy ejemplificativo de ello son las páginas web, los inúmeros blogs y perfiles de Twitter y Facebook dedicados a esta categoría narrativa-adjuntamos al final de nuestro trabajo una lista que no pretende de ningún modo ser exhaustiva sino meramente sintomática 
de la expansión de este discurso literario en lengua portuguesa, española y catalana en Internet. Desde grupos y páginas de referencia académica ineludible, como Redmini (http://redmini.net), Portal dos Microcontos (http://seabra.com/microcontos) o la Internacional Microcuentista (http://revistamicrorrelatos.blogspot.com), pasando por revistas en formato electrónico, como El cuento en red (http:/ / cuentoenred.xoc.uam.mx/), la revista Veredas (ahora minicotos.com.br), la ya extinta Minguante, el blog de la primera biblioteca especializada en el microrrelato (http://lamicrobiblioteca.blogspot.com), hasta llegar a bitácoras y perfiles en Twitter o Facebook de calidad discutible, son muchos los ejemplos que sin duda representan el movimiento de democratización, para no decir banalización, del microrrelato. Tal y como el escritor Rubén Abella expresó en un acto público recientemente, hoy día habrá más escritores que lectores de narrativa brevísima.

Empero, aparte de la cuestión de la difusión, Internet también propicia al microrrelato dialogar con otras esferas artísticas, comunicativas y mediáticas, como es, por poner ejemplos, la imagen, el vídeo, el juego electrónico o la canción. ${ }^{3}$ Esta faceta, ya enunciada por Émilie Delafosse (2013), si bien todavía poco explorada, es, en nuestra opinión, en donde el microrrelato más identidad podría recobrar en el panorama de la literatura digital, ya que las características que anteriormente apuntamos son las ideales para el desarrollo de un discurso literario transmediático y tendencialmente interactivo.

En ese sentido han caminado autores y obras como El valls del tiempo, proyecto colaborativo entre diversos escritores y dibujantes que, aunque en sentido exacto se trata de una micronovela dividida por microrrelatos, es un ejemplo de obra colectiva publicada por entregas en el blog microcienmanos.blogspot.com, en donde cada capítulo está a cargo de un escritor y de un ilustrador, confiriéndole simultáneamente a cada una de sus partes - textual y visual- un valor autónomo y singular.

Otro proyecto interesante, es 18:30, de Samir Mesquita, autor ya del proyecto interactivo Dois Palitos (proyecto en donde el lector tiene acceso a la lectura de microrrelatos a través de la selección de las cerillas que componen una caja de fósforos), y que, en este caso, recurre al motivo del tráfico automovilístico para hacer corresponder a algunos de los coches que integran la imagen de fondo principal un enunciado verbal relacionado con el tema contextual. Cada uno de estos enunciados, intencionalmente acompañados de juegos lingüísticos, encajan en frustraciones, desahogos y exaltaciones vividos por los personajes, y que aquí atañen los eventuales ocupantes de los vehículos que conforman el atasco:

\footnotetext{
${ }^{3}$ Sobre esto, consultar Noguerol, Francisca (2008). "Minificción e imagen: cuando la descripción gana la partida." La era de la brevedad. El microrrelato hispánico. AndresSuárez, I. y A. Rivas. Palencia: Menoscuarto. 183-206; Navarro Romero, Rosa María (junio 2014). "Literatura breve en la red: el microrrelato como género transmediático." Tonos Digital 27: 1-12.
} 


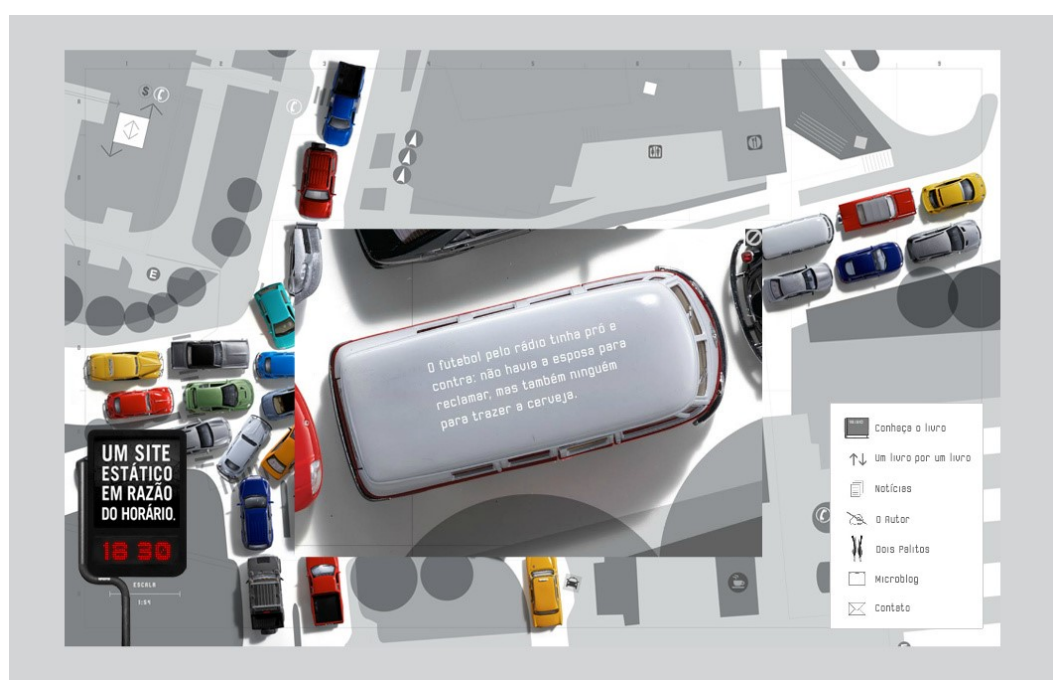

Figura 2. Captura de pantalla del proyecto 18:30, de Samir Mesquita.

Pese a que el contenido textual sea en algunos casos demasiado pobre y carente de vigor y eficiencia en la transmisión de un valor estético, el proyecto gana en asimilar y aproximar distintos lenguajes (interpelando a una pequeña interacción del lector-usuario) que se complementan de modo coherente y que atribuyen una significación propia y única a la obra.

Otro modelo, que actúa sobre otras bases, es miQRocontos, de Carlos Seabra. En este caso no vemos el recurso a diferentes medios de expresión, sino el uso del código QR como codificador de un microrrelato. Cabe al lector, mediante el uso de su Smartphone, a través de la respectiva aplicación, abrir el descodificador y revelar por su cuenta el microrrelato encriptado:

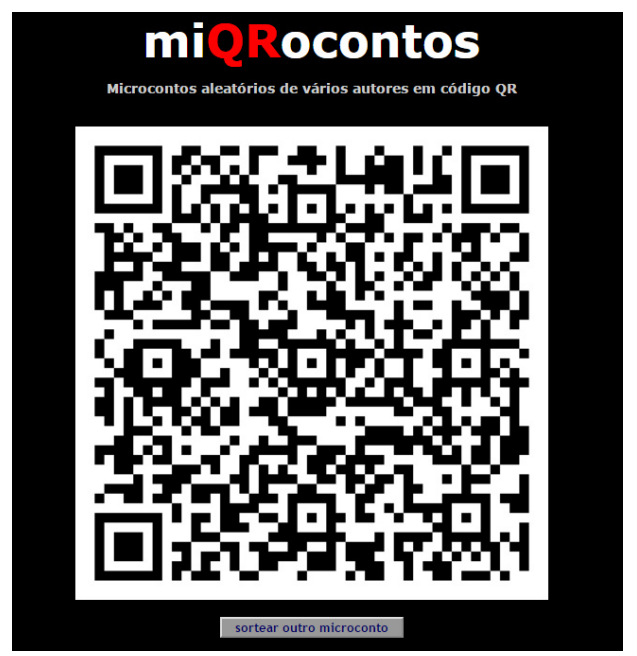

Figura 3. Captura de pantalla del proyecto miQRocontos, de Carlos Seabra. 


\section{Conclusión}

Quizá el ejercicio que acabamos de ejecutar de sistematización de las características del microrrelato compatibles con el World Wide Web sea resultado de una visión un tanto idealizada y abstracta del microrrelato. Tampoco queremos con este estudio declarar una superioridad del texto microficcional sobre los otros textos literarios dentro del entorno virtual ni tampoco defenderlo sobre todos los demás, sino señalar, como hemos intentado elucidar, la sencillez de acomodación del microrrelato como categoría literaria a Internet. No somos, por lo tanto, de la opinión que la Red vino a propulsar la reducción drástica de lecturas de obras tradicionalmente largas, como las novelas, en favor de textos más breves, no solo porque hasta donde sabemos, no haya datos que corroboren que la novela - tomamos el ejemplo del subgénero literario tendencialmente largo y complejo en extensión - sea un género literario en crisis. Eso sí, aparte de la histeria alrededor de las aportaciones de las redes sociales virtuales en nuestro cotidiano y del rescate de géneros literarios hiperbreves como el aforismo o el haikú, el microrrelato ha sabido reivindicar su espacio en el acervo literario en las últimas dos décadas. Pero eso no significa que vaya más allá del standing de 'una tendencia más' de la actualidad literaria, que halla en el mundo digital un medio fértil y eficiente para llegar a más lectores y sin intermediarios como las entidades editoriales. Lo que no quiere decir que, como hemos visto, pese a la grande expansión de obras y autores aficionados al género se verifique un elevado número de propuestas que exploren el microrrelato desde sus potencialidades más visibles en Internet.

Recordemos las palabras de Rui Costa cuando dice:

E quanto ao tamanho? Quanto mais pequeno melhor, como os telemóveis? Pois, a pergunta é traiçoeira, porque os telemóveis só continuaram a diminuir de tamanho até ao ponto em que sua funcionalidade começou a exigir um écran maior. Mas a questão do tamanho parece-me pertinente, quando situada no contexto antropológico que lhe responde: o espaço parece não ser absolutamente infinito quando todos queremos um lugar, ainda que provisório e inseguro. Podemos fazer uma analogia com os livros: se mais pessoas publicam livros, parece natural que os livros tenham um tempo médio de exposição nas livrarias inferior. Isto tem a ver com um fenómeno de democratização em que tempo e espaço (às vezes é difícil distinguilos) aparecem divididos por um maior número de pessoas. $\mathrm{O}$ aparecimento dos blogs enquadra-se neste movimento, e sabemos que os blogs são o grande viveiro actual da micro-ficção (a duração média das visitas na maior parte dos blogs ronda os dois minutos, o que desaconselha a publicação nesses espaços de textos com centenas de páginas. (2008: 1) 
Es así que se entiende que la acomodación del sujeto a estos nuevos tiempos trajo consigo misma nuevos retos en la propia forma de concebir el objeto literario, no solo desde el punto de creación como también de recepción. A fin de cuentas, el derribo de fronteras entre ser humano y máquina, entre mundo empírico y mundo virtual es cada vez más una realidad inminente. Tal vez no estemos así tan distantes de lo que Raúl Sánchez Quiles plasmó en su microrrelato "RIP en RED":

La noche se convirtió en día y el día en noche, los minutos se empastaron con las horas y el tiempo se detuvo. Frente a la pantalla, fuiste perdiendo fuerza hasta que no pudiste comer ni levantarte. Te lo hacías todo encima y encima del teclado dormías. No hizo falta que tu cuerpo desprendiera el olor de la putrefacción, los bomberos echaron la puerta abajo exactamente al tercer día de tu muerte. Nadie te echó físicamente de menos, pero 1000 personas se temieron lo peor cuando tu magnífico blog dejó de actualizarse. (2011: 63)

\section{Agradecimientos}

Los resultados de este trabajo han sido financiados por el Programa de Formación de Profesorado Universitario (FPU) del Ministerio de Educación, Cultura y Deporte.

\section{Referencias}

AARSETH, Espen (1997). Cybertext: Perpectives on Ergodic Literature. Baltimore: The John, Hopkins University Press.

ALONSO, Rosana y Manuel Espada, eds. (2013). Deantología. La logia del microrrelato. Madrid: Editorial Talentura.

ANDRES-SUÁREZ, Irene, ed. (2012). Antología del microrrelato español (19062011). El cuarto género narrativo. Madrid: Cátedra. Letras Hispánicas.

APARICIO, Juan Pedro (2008). "Poética Cuántica." La era de la brevedad. El microrrelato hispánico. Andres-Suárez, I. y A. Rivas. Palencia: Menoscuarto.

CARR, Nicholas (2011). Superficiales. Qué está haciendo Internet con nuestras mentes?. Madrid: Taurus.

CASSANY, Daniel (2012). En línea. Leer y escribir en la red. Barcelona: Anagrama.

CASTANYER, Laura Borràs, ed. (2005). Textualidades electrónicas. Nuevos escenarios para la literatura. Barcelona: Editorial UOC.

CENTURIÓN, Sandro (14 de septiembre de 2009). "Sín título." Capturando Cuentos. 7 jun. 2016. http://leadespacio.blogspot.com.

CHAFFE, Laís (9 de enero de 2013). "Sem título 2." Casa Verde. 7 jun. 2016. http://www.casaverde.art. 
COSTA, Rui (2008). “Sobre a Micro-ficção.” Insónia. 20 abr. 2016. http:/ / antologiadoesquecimento.blogspot.com.es/2008/06/sobremicro-fico-texto-lido-no-encontro.html.

DAWKINS, Richard (1990). The selfish gene. Oxford: Oxford University Press. $2^{\mathrm{da}}$ edición.

DELAFOSSE, Émilie (2013). "Internet y el microrrelato español contemporáneo.” Revista Letral 11: 69-81.

EPPLE, Juan Armando (2005). MicroQuijotes. Barcelona: Thule.

ESCOBAR, Aldo Flores (2015). ¡Nocauts! Microrrelato internacional de boxeo. Puebla: BUAP.

LAGMANOVICH, David (2005). La otra mirada. Antología del microrrelato bispánico. Palencia: Menoscuarto.

(2006). El microrrelato. Teoría e historia. Palencia: Menoscuarto.

LORENZO, Belén (8 de abril de 2011). "Principios." Relatos para leer de pie.... 7 jun. 2016. www.relatosparaleerdepie.blogspot.com.

MESQUITA, Samir (2007). Dois palitos. 7 jun. 2016. http://www.samirmesquita.com.br/doispalitos.html.

ORTIZ SOTO, José Manuel y Fernando Sánchez Clelo, ant. (2013). Alebrije de palabras: Escritores mexicanos en breve. Puebla: BUAP.

POLLASTRI, Laura (2007). El límite de la palabra. Antología del microrrelato argentino contemporáneo. Palencia: Menoscuarto.

QUILES, Raúl Sánchez (2012). "El error." Antología del microrrelato español. (1906-2011). El cuarto género narrativo. Madrid: Ediciones Cátedra. 119.

ROAS, David, ed. (2010). Poéticas del microrrelato. Madrid: Arco/Libros.

SEABRA, Carlos. Microcontos de José Seabra. 10 mayo 2015. http://www.seabra.com/cgi-seabra/contos/randtxt.pl/contos2.html.

SERRANO CUETO, Antonio (2015). Después de Troya. Microrrelatos hispánicos de tradición clásica. Palencia: Menoscuarto.

TRISTINHO (2 de septiembre de 2010). "Serial Killer." Minimo. 1 microficção por dia. http://minimo-microficcao.blogspot.pt/2010/09/catalogo-deespecialidades-medicas-o.html

VALLS, Fernando (2012). Mar de Pirañas. Nuevas voces del microrrelato español. Palencia: Menoscuarto. 


\section{Anexo}

\section{Microrrelato en Portugués}

\subsection{Revistas}

Revista Minguante (dedicada à microficção, desactivada desde 2009).

\section{2. $\mathrm{Blogs}^{4}$}

00:04, de Paulo Rodrigues Ferreira (http://zeromaisquatro.blogspot.com). A casa das mil portas, proyecto colectivo

(http://www.nemonox.com/1000portas/projeto.html). A gaveta do Paulo, de Paulo Kellerman (http:/ / agavetadopaulo.blogspot.com). Antologia do Esquecimento, de Henrique Manuel Bento Fialho

(http://universosdesfeitos-insonia.blogspot.com).

Bicho Ruim, de Rui Manuel Amaral (http:/ / bicho-ruim-blog.blogspot.com). Blog d'Apontamentos (http://blogdapontamentos.blogspot.com).

Blog do Escritor, de Henry Alfred Bugalho

(http://blogdoescritor.oficinaeditora.com/).

Caminho Árduo, de José Eduardo Lopes

(http://caminhoarduo.blogspot.com).

Cão. Antologia de textos com cães dentro, de Henrique Manuel Bento Fialho

(http://weblogdocao.blogspot.com).

Carlos Seabra. Microcontos (http://seabra.com/microcontos).

Casa Verde, de Laís Chaffe (http://www.casaverde.art.br).

Contículos, proyecto colectivo (http://conticulos.blogspot.com).

Contos de cinco palavras, de Rynaldo Papoy

(http://c5p3.blogspot.com) (http://c5p.blogspot.com).

Da day A Fênix Apoplética, de Day (https://carva1.wordpress.com).

Das palavras o espaço, de João Valente (http:/ fromwords.blogspot.com).

De Chaleira, de creación literaria colectiva (http://e-chaleira.blogspot.com).

Edson Rossatto (http://www.edsonrossatto.com).

Ene Coisas (http://luis-ene.blogspot.com).

Ene Problemas, de António (http://nproblemas.blogspot.com).

Escrevinhices, de João Pereira de Matos (http:/ / escrevinhices.blogspot.com).

Esta distância que nos une, de R. (http:/ / estadistancia.blogspot.com).

Histórias da Katherine, de Katherine Kunke

(https://historiasdakatherine.wordpress.com).

Leonardo Brasiliense (http://www.leonardobrasiliense.com).

Kid A, de Alberto Manuel Vieira (http://kidablogue.blogspot.com).

letra minúscula, de José Mário Silva (http://letraminuscula.blogspot.com).

${ }^{4}$ Como se verá a continuación, hemos dado preferencia a blogs y no a referencias a redes sociales como el Twitter o Facebook, por una cuestión de evitar la repetición de contenidos y por la constatación de que los blogs suelen respetar con más fidelidad la vocación literaria para la cual fueron creados. 
Marco, da Literatura?, de Araújo Bueno

(http://wwwaraujobueno.blogspot.com).

MicroArgumentos, de Angela Schnoor (www.microargumentos.blogspot.com).

Microcontos, de Ricardo Oliveira (https://microcontos.wordpress.com).

Microcontos do Carlos, de Carlos Seabra

(http://microcontosdocarlos.blogspot.com).

Microcontos da Zezé, de Zezé Pina (http://microcontoszeze.blogspot.com).

Micro-leituras, de José Lopes (http://micro-leituras.blogspot.com).

Microrelatos do Cheeko, de Chico Pascoal

(http://microrelatosdocheeko.blogspot.com).

Mil e uma pequenas histórias, de Luís Ene (http://1000euma.blogspot.com).

Minicontando, de Ana Mello (http://minicontosanamello.blogspot.com).

Minicontos cotidianos, de Sílvio Vasconcellos y *Hemisfério Norte (http://minicontos.blogspot.com).

Minicontos.com.br, antigua revista Veredas, editado por Ana Mello y Marcelo

Spalding (http://www.minicontos.com.br/).

Mínimo. 1 Microficção por dia, de Tristinho

(http://minimo-microficcao.blogspot.com).

Miniminimos, de *Hemisfério Norte (http://miniminimos.blogspot.com).

Narrativas Mínimas, de Cláudio B. Carlos

(http://narrativasminimas.blogspot.com).

Parlares, de Eugénia Tabosa (http://parlares.blogspot.com).

Pedro e o Lobo, de Pedro Amaral (http:/ /pedroeolobo.blogspot.com).

Penates, de Tiago Moralles (http://tfmoralles.blogspot.com).

Portal dos Microcontos, editado por Carlos Seabra

(http://microcontos.com.br/).

Primeiros Mil microcontos, de Jarbas (http://terceirosmicrocontos.blogspot.com).

O bibliotecário de Babel (http://bibliotecariodebabel.com).

O muro e outras páginas, de Wilson Gorj

(http://omuroeoutraspgs.blogspot.com).

Ossos do Ofidio, de Marcelino Freire (https://marcelinofreire.wordpress.com).

Samir Mesquita (http://www.samirmesquita.com).

Twitteratura. Um microbloguezinho, de Prolixa

(http://twitteratura.blogspot.com).

Textos e Textículos, de Felipe Navarro y Vinícius Borges

(http://inutilidadetextual.blogspot.com.br/search/label/Micro-contos).

\subsection{Redes Sociales}

\section{Facebok}

Amanhã serei gigante (https://www.facebook.com/nanonovela).

Escrita de Microfiç̧ão

(https://www.facebook.com/groups/200348463411803/?fref=ts).

Microcontos (https://www.facebook.com/microcontos). 
O livro dos 1001 microcontos, de Rinaldo de Fernandes

(https://www.facebook.com/O-Livro-dos-1001-microcontos$135222143320481 /$ ?fref $=$ ts).

\section{Flickr}

Sem Ruido (https://www.flickr.com/photos/semruido).

\section{Twitter}

Coletivo Sem Ruido (https:// twitter.com/semruido).

Gustavo do Carmo (https://twitter.com/gustavocarmo2).

Instantâneos (https://twitter.com/Contomicro).

Marcos Bassini (https://twitter.com/microcomicas).

Micro Contos (https://twitter.com/mpc_microcontos).

MicroConto107FM (https://twitter.com/MicroConto107FM).

Microcontos (https://twitter.com/microcontos).

Programa \#MicroConto (https://twitter.com/microconto).

Samir Mesquita (https://twitter.com/samirmesquita).

Versos e Microcontos (https:// twitter.com/meus_continhos).

\subsection{E-Books y Otras Actividades de Difusión del Microrrelato}

Cem toques cravados, de Edson Rossatto. São Paulo: Andross, 2010

(https://catracalivre.com.br/wp-

content/uploads/2010/11/cemtoques_miolo_1cap.pdf).

Dois Palitos, de Samir Mesquita

(http://www.samirmesquita.com.br/doispalitos.html) Proyecto.

Labirintos Sazonais

(http:/ / labirintos-sazonais.com) Proyecto de Literatura Digital.

Microcontos, minijóias. Rosana de Mont'alverne Neto (org.). Belo Horizonte:

Editora Aletria, 2009.

(http://biblioo.info/blogdochicodepaula/wp-

content/uploads/2014/10/livro_microcontos_minijoias.pdf) E-book.

Minicontos coloridos, de Marcelo Spalding

(http://www.literaturadigital.com.br/minicontoscoloridos) Proyecto.

Minicontos e muito menos, de Marcelo Spalding

(http://www.artistasgauchos.com.br/ww-minimenos/) E-book.

Minicontos de ouvir. Projeto de literatura digital para pessoas com deficiência visual. Ou não. (http://www.literaturadigital.com.br/minicontosdeouvir) Proyecto.

Miqrocontos. Microcontos aleatórios de vários autores em código $Q R$.

(http://seabra.com/qrcontos/) Proyecto.

Releituras. Os melhores textos dos melhores escritores.

(http://www.releituras.com) Página web.

Tamanho não é doc, Henry Alfred Bugalho (org.)

(http://static.recantodasletras.com.br/arquivos/1662440.pdf) E-book.

Tamanho não é docII, Henry Alfred Bugalho (org.)

(http://docslide.com.br/documents/tamanho-nao-e-doc.html) E-book. 


\section{Microrrelato en Español y Catalán}

\subsection{Revistas}

Brevilla. Revista de Minificción (http://revistabrevilla.blogspot.com). E-Kuóreo. Revista de minicuentos (http://e-kuoreo.blogspot.com).

El Cuento en Red. Revista electrónica de teoría de la ficción breve

(http://cuentoenred.xoc.uam.mx/).

Fix 100. Revista hispanoamericana de ficción breve

(http://cpecperu.org/docs/index.php?option=com_wrapper\&Itemid=79).

Internacional Microcuentista. Revista de lo breve

(http://revistamicrorrelatos.blogspot.com).

Microfilias (http:/ / www.microfilias.org).

MiNatura. Revista digital de lo breve y lo fantástico

(http://www.servercronos.net/bloglgc/index.php/minatura).

Plesiosaurio. Revista de ficción breve peruana

(http://revistaplesiosaurio.blogspot.com).

\subsection{Blogs de Difusión del Microrrelato (Académicos, Críticos y de} Autores que Publican en la Red)

150 por día, de Walter G. (http:/ / cientocincuentapordia.blogspot.com).

365 microcuentos, de Sir Helder Amos (http:/ /www.365microcuentos.com).

abraPalabramágica la Magia de la palavra, de Héctor Marcial

(http://abrapalabramagica.blogspot.com).

Al borde de la palabra. Microcuentos

(http://albordedelapalabra-microcuentos.blogspot.com).

Anillos Invisibles, de María del Pilar (http://anillosinvisibles.blogspot.com).

Antología Mundial de Minificción, de Rony Vásquez

(http://antologiamundialdeminificcion.blogspot.com).

Antologia virtual de minificción mexicana

(http://1antologiademinificcion.blogspot.com).

Arca ficticia. Archivos del taller de minificciones de ficticia

(http://arcaficticia.com).

Autora desconocida. Una búsqueda textual, de autoradesconocida

(http://autoradesconocida.blogspot.com).

Bificciones (http://bificciones.blogspot.com).

Borrón y cuento nuevo, de NiñoCactus

(http://borronycuentonuevo.blogspot.com).

Calarcá (http://www.calarca.net/\#minificciones).

Caleidoscopio, de Xavier Blanco (http:/ / xavierblanco.blogspot.com).

Capturando cuentos, de Sandro Centurión (http://leadespacio.blogspot.com).

Carlos Burgos (https://laleydeotros.wordpress.com).

Clinica de microficción del escritor Edgardo Ariel Epherra

(http://clinicademicroficcion.blogspot.com).

Cortitos, de Claudia Sánchez (http://sanchezclaudiabe.blogspot.com). 
Cuentos y más. La página de los textos cortos

(http://www.cuentosymas.com.ar/blog).

Dakota de Alejandro Bentivoglio (http://memoriasdeldakota.blogspot.com).

Dannyblog, de Daniel Frini (http://danielfrini2.blogspot.com).

De las aves que vuelan me gusta el chancho, de Fabián Vique

(http://delasavesquevuelan.blogspot.com).

Documenta mínima. Literatura condensada en la era de la brevedad

(http://documentaminima.blogspot.com).

El baile de los silenos, de Antonio Serrano Cueto

(http:/ / antonioserranocueto.blogspot.com).

El detonador astral, de Gustavo Tisera

(http://eldetonadorastral.blogspot.com).

El doctor Frankenstein, supongo, de Jesús Esnaola

(http:/ / frankensteinsupongo.blogspot.com).

El elefante funambulista, de Gabriel Bevilaqua

(http:/ / elefantefunambulista.blogspot.com).

El final del cuento, de Dídac Marín (https:/ / fotosamagades.wordpress.com).

El inconfesable vértigo de la mujer baja, de Miriam Márquez (http://miriammarquez.blogspot.com).

El living sin tiempo. Microficciones y cuentos breves, de Martín Gardella

(http://livingsintiempo.blogspot.com).

El microrrelatista, de Torcuato (http://elmicrorrelatista.blogspot.com).

El rincón de Nicolás Jarque, de Nicolás Jarque

(http://escribenicolasjarque.blogspot.com).

En 99 palabras, de Miguel Ángel Molina (http://en99palabras.blogspot.com).

En los esteros. Sitio de microrrelatos, de Antonio Cruz

(http://enlosesteros.blogspot.com).

Entre bonsais, de César Socorro (https://cesarsocorro.wordpress.com).

Escríbeme una ilustración, de Clara Varela

(http://escribemeunailustracion.blogspot.com).

Esta que ves, de Patricia Nasello (http://patricianasello547.blogspot.com).

Ficticia. Ciudad de cuentos e historias (http://www.ficticia.com).

Ficción breve venezolana (http:// ficcionbreve.org/site/home.php).

Ficción minima (http:/ / ficcionminima.blogspot.com).

Filias' bome, de Izaskun Albéniz (http://misfiliasyfobias.blogspot.com).

Fotorrelatos, de Dídac Marín y Anna Uribe (http://www.cuentossinfinal.com).

Grimas y leyendas, de David Vivancos (http://grimasyleyendas.blogspot.com).

Hacedor de miniaturas, de Rodrigo E.

(http:/ / hacedordeminiaturas.blogspot.com).

Historias mayúsculas en porciones minúsculas, de Maite García

(http://microrrelatosenporciones.blogspot.com).

Hiperbrevedades, de svor (http://hiperbrevedades.blogspot.com).

Hiperbreves S. A., de Raúl Sánchez Quiles (http://hiperbreve.blogspot.com).

Ildiko txt, de Ildiko Nassr (http:/ /ildikotxt.blogspot.com). 
La cuentoteca de Miguel Dorelo (http:/ /lacuentoteca.blogspot.com).

La espada oxidada, de Manu Espada (http://manuespada.blogspot.com).

La ley de otros. Crónicas costumbristas marsupiales y otros desechables, de

Máquina de coserpalabras, de Juan Yanes (http://jyanes.blogspot.com).

La libreta digital, de Francisco M. Ortega (http://libretadigital.blogspot.com).

La meva perdició, de Sergi G. Oset (http://lamevaperdicio.blogspot.com).

La microbiblioteca, de la Bib. Barberà del Vallès Esteve Paluzie, especializada en microrrelato

(http://lamicrobiblioteca.blogspot.com);(http:// diariumbarbera.blogspo t.com).

La nave de los locos, de Fernando Valls (http://nalocos.blogspot.com).

La pluma y el escalpelo, de Raúl Brasca

(http://webs.uolsinectis.com.ar/rbrasca/).

Laboratorio de microcuentos (http://miniimaginario.blogspot.com).

Laboratorio de minificciones (http://minificcionario.blogspot.com).

Lágrimas para cactus, de Pedro Peinado

(https://lagrimasparacactus.blogspot.com).

Laura Nicastro (http://lauranicastro.blogspot.com).

Letra chica, de Eduardo Mancilla (http://casimicrocuentos.blogspot.com).

Letras de escarcha, de Pablo de la Rúa

(https://letrasdeescarcha.wordpress.com).

Lola Sanabria, de Lola Sanabria (http://lolasanabria.blogspot.com).

Los cuentitos de Esteban Dublín, de Esteban Dublín

(http:// estebandublin.blogspot.com).

Los cuentos del can cerbero (http:/ / cuentosdelcancerbero.blogspot.com).

Más claro, agua (http:/ /masclaroagua.blogspot.com).

Medio siglo de Sergio Gaut, Daniel Frini, Ogui y Patricio Bazan

(http://mediosiglocuentos.blogspot.com).

Mentira como la vida misma, de Uno

(http://mentiracomolavidamisma.blogspot.com).

Merienda en el parque, de Javier López

(http://meriendaenelparque.blogspot.com).

Mi antologia de microcuentos, de Daniel Frini (http://danielfrini3.blogspot.com).

Microcuentos, de Julio Maturana (http://solomicrocuentos.blogspot.com).

Microcuentos de Blis, de Blis (http://microcuentosdeblis.blogspot.com).

Microcuentos/muestrario (http://microcuentosmuestrario.blogspot.com).

Microcuentos $y$ otras historias, de Pedro Alonso

(http://microcuentosyotrashistorias.blogspot.com).

Microletras. Historias para beber de um trago, de José Javier

(http://microletras.blogspot.com).

Microliteratura Nicaragüense (http://microliteraturanica.blogspot.com).

Micrópolis (http://micropolis.pe).

Microrrelato catalán (http:/ /a-bona-confitura.blogspot.com). 
Microrrelatos a peso, de Daniel Sánchez Bonet

(https://microrrelatoapeso.wordpress.com).

Microrrelatos al por mayor, de Luisa Hurtado

(http://microrrelatosalpormayor.blogspot.com).

Microrrelatos y Microcuentos, de Ana Callegaris

(http://microrrelatosymicrocuentos.blogspot.com).

Microrréplicas, de Andrés Neuman (http://andresneuman.blogspot.com).

MicroSeñales de Humo, de David Moreno Sanz

(http:// xn--microsealesdehumo-lxb.blogspot.com).

Microsergirelatos, de Sergi Cambrils (http://microsergirelatos.blogspot.com).

Minificciones publicadas en la revista de Edmundo Valadés "El cuento», de Alfonso

Pedraza (https://minisdelcuento.wordpress.com).

Minimalismos (http://minimalismoscuentos.blogspot.com).

Minitextos, de José Luis Rodríguez (http://www.minitextos.org).

Mis historias, de Yolanda Nava (http://microsyotrashistorias.blogspot.com).

Mundo en un grano de arena, de Ángeles Sánchez

(http://mundoenungranodearena.blogspot.com).

Nana Rodríguez Romero (http://wwwnanarodriguez.blogspot.com) .

Narrativa Breve, editado por Francisco Rodríguez Criado

(http://narrativabreve.com).

No Comments (http://nocomentsno.blogspot.com).

Ocurrió en febrero, de Maribel Romero (http:/ / ocurrienfebrero.blogspot.com).

Ojo Travieso, de Lilian Elphick (http://lilielphick.blogspot.com).

Parpadeos, colectivo Ráfagas (http://rafagasparpadeos.blogspot.com).

Pativanesca, de Elisa de Armas (http://pativanesca.blogspot.com).

Patricia Nasello. Microrrelatos (http://patricianasello.blogspot.com).

Primera Antología binacional de microficciones argentinochilenas

(https://ardenandes.wordpress.com).

Propilogo, de Gabriel de Biurrun Baquedano

(http://propilogo.blogspot.com).

Proyecto de conversión de las grandes obras de literatura universal en microrrelatos (http://proyectocelsius.blogspot.com).

Quimicamente impuro (http:/ quimicamenteimpuro.blogspot.com).

Realidades para lelos, de Víctor Lorenzo Cinca

(http://realidadesparalelos.blogspot.com).

Redmini. Red Internacional de Investigadores de Minificción

(http://redmini.net).

Reflexiones desde la bubardilla, de Luis Gonzalí

(http://lgonzali.blogspot.com).

Relatos de andar por casa, de Anita Dinamita

(http://relatosdeandarporcasa.blogspot.com).

Relatos Encallados (https://gotzoki.wordpress.com).

Relatos para ler de pie, de Belén Lorenzo

(http://relatosparaleerdepie.blogspot.com). 
Sin ton ni son, de Héctor Rivero

(http:/ / cuentosycuentinimos.blogspot.com).

Sueños en la memoria, de Gemma Pellicer

(http://megasoyyo.blogspot.com).

Teoría del minimo relato, de Fernando Sánchez Ortiz

(http://minimorrelato.blogspot.com).

Todo nuevo bajo la luna, de Turcuato González

(http:/ / todonuevobajolaluna.blogspot.com).

Un cuento en tu oído, de Rufino U. Sánchez

(http://uncuentoentuoido.blogspot.com).

Vení te cuento, de Guillermo Castillo (http://venitecuento.blogspot.com).

\subsection{Redes Sociales}

\section{Facebook}

Luisa Valenzuela (https://www.facebook.com/luisavalenzuelaescritora).

Microrrelatos Ilustrados, de Sara Lew

(https://www.facebook.com/microrrelatosilustrados).

\section{Twitter}

\#microcuentos (https://twitter.com/SonMicroCuentos).

Bruno (https://twitter.com/Bruno_Kaz?ref_src=twsrc\% $\% 5$ Etfw).

Diario de Cuentos (https://twitter.com/DiariodeCuentos).

Javier Callejo (https://twitter.com/javierdemoguer).

José Luis Zarate (https://twitter.com/joseluiszarate?ref_src=twsrc\%5Etfw).

Microcuentos (https://twitter.com/microcuentos).

Microficción (https://twitter.com/Miqrocuento).

Microrrelatos (https://www.facebook.com/minificcion/?fref=ts).

Plácido Romero (https:/ / twitter.com/PlcdRmr?ref_src $=$ twsrc $\% 5 E t f w)$.

\subsection{E-Books de Acceso Libre, Talleres y Otras Actividades de Difu- sión del Microrrelato en la Red}

I Antología Literaria Digital de El narratorio.

(http://issuu.com/elnarratorio/docs/el_narratorio_antol__literaria_digi/ $53 ? \mathrm{e}=0 / 34166979)$.

Antología de microrrelatos de amory desamor

(http://issuu.com/amaranta/docs/amor_desamor_brevilla/3?e=103942

3/36160216).

Audioantología de microrrelatos españoles e hispanoamericanos bajo el tema de la vejez. (https://soundcloud.com/pablogonz-2/viejos-amigos-una-aproximaci-n).

\section{Cienmanos}

(http://issuu.com/dididibujos.blogspot.com/docs/dididibujos.blogspot. com $/ 95 ? \mathrm{e}=0)$ Micronovela.

De viaje. Antología de microrrelatos en la red

(http://issuu.com/manolortiz/docs/de_viaje3/5?e=0). 
Destellos en el cristal. Antología de microrrelatos de espejos

(https://issuu.com/internacionalmicrocuentista/docs/destellos_en_el_c ristal_final?e $=5635252 / 1986668)$.

E-book (Tweet book) que recoge los tuits de nohubounavez

(http://pt.calameo.com/books/000202958c72725b8052c).

Ficticia punto com

(https: / / issuu.com $/$ marinaficticia $/$ docs $/$ minificciones $201309 ? \mathrm{e}=946086$

1/5502932) Resultado del taller de minificciones.

Grandes microrrelatos del 2011, seleccionados por Internacional Microcuentista

(https://issuu.com/internacionalmicrocuentista/docs/grandes_microrre latos_de_2011?e=5635252/1986749).

Grupo de Google+ de la Biblioteca Barberà

(https://plus.google.com/113787901828524169865).

La microbiblioteca

(https://issuu.com/bibliotecabarbera/docs/microbiblioteca2014_-cast)

III Microconcurso.

Taller online de formación en microficción, de Violeta Rojo

(https://tallerdemicrocuentos.wordpress.com/).

Taller de escritura creativa de Clara Obligado, centrado en talleres de narrativa (http://talleresdeescrituracreativa.blogspot.com).

Programa de divulgación literaria de la Radio Nacional de España, dirigida por Juan Jacinto Muñoz Rengel (http://rne.literaturaenbreve.com).

(C) 2016 Ana Sofia Marques Viana Ferreira. Licensed under the Creative Commons Attribution-NoncommercialNo Derivative Works 4.0 International (CC BY-NC-ND 4.0). 